\title{
Levantamento Fitossociológico de Plantas Daninhas em Calçadas do Município de Paraguaçu Paulista-SP ${ }^{1}$
}

\author{
Phytosociological Assessment of Weeds on Paraguaçu Paulista-SP Sidewalks
}

MACIEL, C.D.G. ${ }^{2}$, POLETINE, J.P. ${ }^{2}$, OLIVEIRA NETO, A.M. ${ }^{3}$, GUERRA, N. ${ }^{3}$ e JUSTINIANO, W. ${ }^{3}$

\begin{abstract}
RESUMO - Com o objetivo de identificar as comunidades de plantas daninhas que ocorrem nas calçadas do municipio de Paraguaçu Paulista-SP, foi realizado um levantamento fitossociológico considerando três possiveis posicionamentos de ocorrência da infestação em calçadas. As plantas daninhas foram identificadas e quantificadas em todos os principais bairros do municipio, sendo subdivididos 180 pontos de amostragem em faixas posicionadas nas regiões: guia da calçada, centro da calçada e beiral do muro. No levantamento, foram identificadas 11 famílias e 21 espécies; as famílias Poaceae, Asteraceae, Euphorbiaceae e Amaranthaceae foram as que registraram os maiores números e frequências de espécies, nas três posições das calçadas. Os maiores indices de valor de importância (IVI) das espécies identificadas na guia e no centro da calçada foram, respectivamente: Eragrotis pilosa (50,3 e $56,6)$, Chamaesyce prostrata $(48,2$ e 57,6) e Chamaesyce hirta $(30,3$ e 36,4); e para o beiral do muro: C. prostrata $(60,6)$, Phyllanthus tenellus $(44,3)$ e C. hirta $(36,2)$.
\end{abstract}

Palavras-chave: identificação, infestação, vias públicas.

\begin{abstract}
A phytosociological assessment was carried out to identify weed communities occurring on the sidewalks of Paraguacu Paulista-SP, considering three possible types of weed infestation on sidewalks. Weeds were identified and quantified in all the main neighborhoods of this municipal district, being subdivided into 180 sampling points in strips positioned on the curb line of the sidewalk, the center of the sidewalk and the edge of the wall. Eleven families and 21 species were identified with the Poaceae, Asteraceae, Euphorbiaceae and Amaranthaceae families registering the highest numbers and frequencies of species in the three side walk positions. The highest importance value indices (IVI) for the species identified in the curb lineand center of the sidewalk were: Eragrotis pilosa (50.3 and 56.6), Chamaesyce prostrata (48.2 and 57.6) and Chamaesyce hirta (30.3 and 36.4); for the edge of the wall, the highest IVI were: C. prostrata (60.6), Phyllanthus tenellus (44.3) and C. hirta (36.2).
\end{abstract}

Keywords: identification, infestation, public streets.

\section{INTRODUÇÃO}

As plantas daninhas podem ocorrer em qualquer lugar onde haja possibilidade de se desenvolver uma espécie vegetal. Assim, não é dificil prever que ocorram em áreas destinadas a lazer, paisagismo, indústrias, parques, rodovias, ferrovias e ambientes urbanos, causando transtornos, riscos e prejuízos à beleza dos locais (Deuber, 1997).
Segundo Schneider (2007), perturbações no ambiente natural potencializam a dispersão e estabelecimento de plantas daninhas, especialmente após a diminuição da diversidade natural. Essas perturbações são de origem antrópica, intima e amplamente correlacionadas à atividade humana, como agricultura, pecuária, desmatamento, construção de cidades, ferrovias, ruas e estradas, remoção da vegetação natural,

1 Recebido para publicação em 23.5.2009 e na forma revisada em 12.3.2010.

2 Professor, Dr., Dep. de Fitotecnia da Escola Superior de Agronomia de Paraguaçu Paulista - ESAPP/FUNGE, $19700-000$ Paraguaçu Paulista-SP < macielconsultoria@hotmail.com>; ${ }^{3}$ Acadêmicos de Agronomia, ESAPP/FUNGE. 
acúmulo de lixo e uma série de outras modifícações.

Nas calçadas das vias públicas, a infestação de plantas daninhas é tida como problema, uma vez que, além de alterar a estética da pavimentação e em muitos casos dificultar a passagem dos pedestres, obriga as prefeituras periodicamente a investir em medidas de controle, com o uso de herbicidas ou mesmo capinas mecanizadas ou manuais, para evitar o seu avanço. Ao contrário disso, Carneiro \& Irgang (2005) afirmam que, com a expansão das áreas urbanas e a influência humana cada vez maior no ambiente, a vegetação urbana pode ser importante devido a uma maior aproximação dos habitantes com a natureza, assim como consideram que plantas que nascem em muros entre pedras e calçamentos quebram a monotonia do concreto e adicionam interesse visual e biodiversidade.

Nesse sentido, a metodologia mais utilizada no reconhecimento florístico de áreas agrícolas ou não é o estudo fitossociológico, o qual envolve as inter-relações de espécies em uma localidade e tempo determinado. Segundo Blanco (1985), todas as definições de plantas daninhas envolvem caráter econômico ou de indesejabilidade, e o método fitossociológico ou mesmo quantitativo permite avaliar momentaneamente a composição da vegetação.

$\mathrm{O}$ investimento em métodos eficientes que auxiliem no conhecimento da comunidade infestante, por meio da identificação e frequência das espécies prevalecentes, é de fundamental importância, uma vez que a característica da população é que direcionará o tipo de manejo a ser adotado, como e quando (Deuber, 1997; Erasmo et al., 2004). Dessa forma, o entendimento científico dessa vegetação contribuirá para o conhecimento da flora infestante regional e do ambiente no qual ela é encontrada.

Estudos florísticos e fitossociológicos realizados em áreas urbanas podem apresentar grande biodiversidade. Schneider \& Irgang (2005) identificaram 244 espécies, 181 gêneros e 57 famílias em levantamento florístico e fitossociológico da vegetação viária de Não-Me-Toque-RS, no qual as famílias Asteraceae $(25,4 \%)$, Poaceae $(13,5 \%)$ e Fabaceae $(6,7 \%)$ foram as que apresentaram as maiores ocorrências do total de espécies. Carneiro \& Irgang (2005), estudando a origem e distribuição geográfica de espécies ruderais em algumas regiões do Estado do Rio Grande do Sul, identificaram 302 espécies distribuídas em 68 famílias, entre as quais 180 são nativas da região, 97 são exóticas e 25 não tiveram origem determinada.

Este trabalho teve como objetivo identificar e quantificar as espécies de plantas daninhas que ocorrem nas calçadas de vias públicas do município de Paraguaçu Paulista-SP, por meio de levantamento fitossociológico.

\section{MATERIAL E MÉTODOS}

O trabalho foi desenvolvido em novembro de 2006, nas calçadas públicas do município de Paraguaçu Paulista-SP, região pertencente ao Médio Vale do Paranapanema, localizado em altitude média de $506 \mathrm{~m}$, com latitude de $22^{\circ} 34^{\prime} 53^{\prime \prime}$ e longitude de 50³4'35" W.

No levantamento fitossociológico foram avaliados 180 pontos amostrais, distribuídos em todos os principais bairros do município, os quais foram subdivididos em faixas posicionadas nas regiões: a) guia da calçada representada pela soleira ou limite entre o asfalto e início da calçada $\left(2 \mathrm{~m}^{2}=0,5 \times 4,0 \mathrm{~m}\right)$; b) centro da calçada - representada pela região de circulação dos pedestres $\left(3 \mathrm{~m}^{2}=\right.$ $0,75 \times 4,0 \mathrm{~m}$ ); e c) beiral do muro - onde normalmente são formados por rachaduras ou fendas $\left(1 \mathrm{~m}^{2}=0,25 \times 4,0 \mathrm{~m}\right)$, conforme ilustrado na Figura 1. Na escolha dos pontos amostrais, decidiu-se pela não utilização de calçadas muito deterioradas e que expõem grande quantidade de solo, a fim de identificar somente as espécies que realmente emergiram devido a sua capacidade de se adaptar às condições do ambiente e não em razão de outros fatores, como a falta de manutenção da calçada.

O sistema de classificação adotado como base foi o Angiosperm Phylogeny Group APG II (2003), com auxílio das delimitações das famílias e ordenamento de alguns gêneros, conforme Souza \& Lorenzi (2005). Entretanto, na identificação e quantificação das espécies também foi utilizada literatura específica (Kissman \& Groth, 1997, 1999, 2000; Lorenzi \& Souza, 2001; Lorenzi, 2006, 2008), além de 


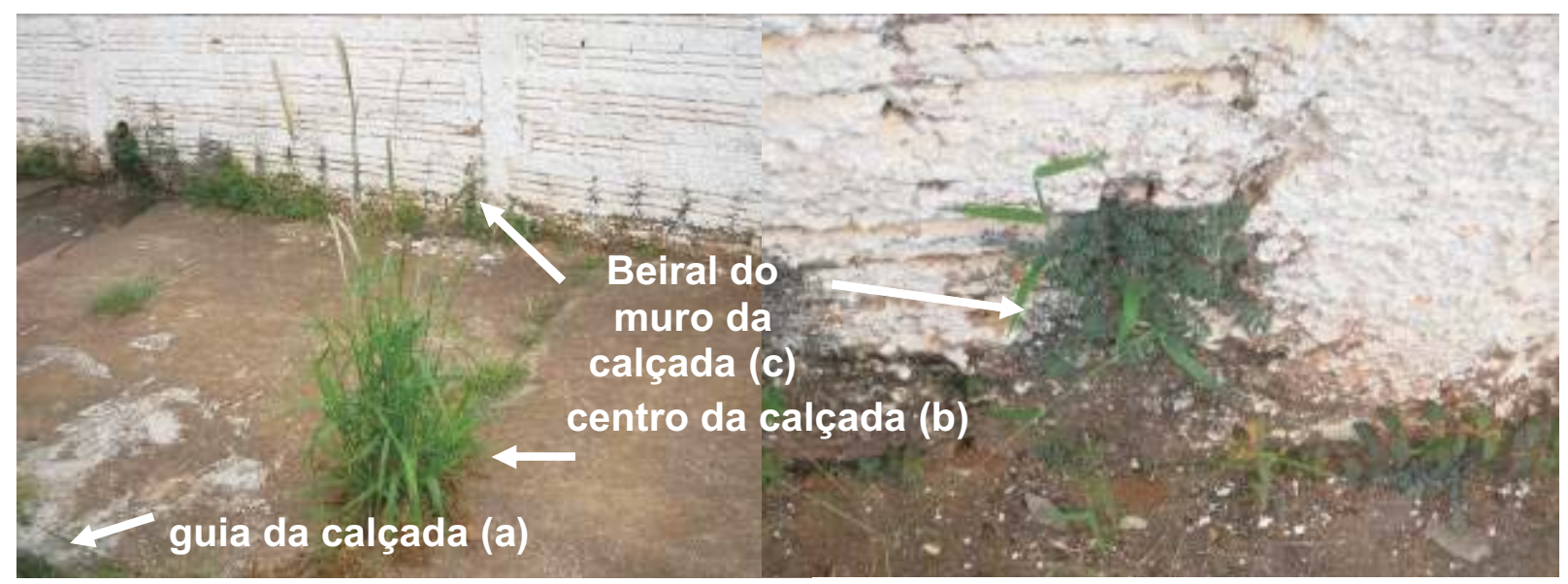

Figura 1 - Ilustração esquemática da disposição das plantas daninhas em calçadas públicas, referente ao método de amostragem, e posicionamentos (a, b e c) utilizados no levantamento florístico.

livros sobre plantas medicinais, ornamentais, dissertações e teses relacionadas ao assunto.

As amostragens foram realizadas de forma semelhante às metodologias descritas por Brandão et al. (1998), Lara et al. (2003), Schneider \& Irgang (2005) e Schneider (2007). Esse procedimento caracterizou-se pela identificação e quantificação das espécies espontâneas utilizando metodologia semelhante à do quadrado inventário $\left(0,25 \mathrm{~m}^{2}\right)$. Das espécies identificadas, foram calculados os parâmetros fitossociológicos: número de indivíduos por espécie; número de parcelas em que a espécie estava presente; frequência (indice da ocorrência das espécies em cada quadrado); densidade (indice da quantidade de indivíduos de uma mesma espécie em cada quadrado); abundância (concentração das espécies nos diferentes pontos da área total); frequência relativa, densidade relativa e abundância relativa (relaciona uma espécie a todas as demais encontradas nas áreas); e índice de valor de importância. No cálculo das referidas variáveis foram utilizadas as seguintes fórmulas, segundo Mueller-Dombois \& Ellenberg (1974):

$$
\text { Frequência }(\text { Fre })=\frac{n^{\underline{0}} \text { de parcelas que contêm a espécie }}{n^{\underline{0}} \text { total de parcelas utilizadas }}
$$$$
\text { Densidade }(\text { Den })=\frac{\mathrm{n}^{\mathrm{o}} \text { total de indivíduos por espécie }}{\text { área total coletada }}
$$$$
\text { Abundância }(\mathrm{Abu})=\frac{\mathrm{n}^{\underline{0}} \text { total de indivíduos por espécie }}{\mathrm{n}^{0} \text { total de parcelas contendo a espécie }}
$$

$$
\text { Frequência Relativa }\left(\text { Frr) }=\frac{\text { frequência da espécie x } 100}{\text { frequência total de todas as espécies }}\right.
$$




$$
\begin{aligned}
& \text { Densidade Relativa }(\text { Der })=\frac{\text { densidade da espécie } \times 100}{\text { densidade total de todas as espécies }} \\
& \text { Abundância Relativa }(\mathrm{Abr})=\frac{\text { abundância da espécie x } 100}{\text { abundância total de todas as espécies }}
\end{aligned}
$$

Índice de Valor de Importância (IVI) = Frr + Der + Abr

\section{RESULTADOS E DISCUSSÃO}

O levantamento fitossociológico das plantas daninhas realizado nas calçadas do município de Paraguaçu Paulista-SP identificou 2.909 indivíduos, distribuídos em 11 famílias e 21 espécies. O beiral do muro e a guia das calçadas apresentaram maior diversidade de espécies em relação à região central da calçada. As famílias Poaceae (5), Asteraceae (4), Amaranthaceae (3) e Euphorbiaceae (2) foram as que apresentaram os maiores números de espécies presentes no levantamento, considerando uma análise geral dos três posicionamentos estudados nas calçadas (Tabela 1).

Esses resultados corroboram os obtidos por Schneider \& Irgang (2005), os quais identificaram em vegetação viária (ou ruderal) de NãoMe-Toque-RS sete espécies pertencentes à familia Poaceae entre as 10 principais. Também identificaram a família Poaceae entre as mais representativas em número de espécies Yanagizawa \& Maimoni-Rodella (1999), em agrossistemas de nogueira e abacateiro; Maciel et al. (2008), em gramados de Paspalum notatum; Guimarães et al. (2002), em área natural e antropizada de uma vereda; Tuffi Santos et al. (2004), em pastagens degradadas em áreas de várzea; e Silva et al. (2008), em parque público. Apesar da diversidade dos ambientes amostrados por esses autores, a dominância da família Poaceae em áreas tão distintas enfatiza a plasticidade das espécies. Segundo Holm et al. (1991), várias espécies da família Poaceae são perenes e produzem grande quantidade de sementes, o que aumenta o seu poder de disseminação e colonização de diferentes ambientes, mesmo em condições inóspitas.
Quanto ao parâmetro fitossociológico frequência relativa, as espécies Eragrotis pilosa, Chamaesyce prostrata e Eleusine indica foram as que mais se destacaram na posição da guia e região central das calçadas, com, respectivamente: 19,5 e 22,2\%; 17,4 e 20,5; e 10,7 e $18,1 \%$. Entretanto, na posição do beiral do muro, as principais espécies foram C. prostrata $(23,4 \%)$, Phyllanthus tenellus $(18,1 \%)$, Chamaesyce hirta $(12,1 \%)$ e Amaranthus deflexus (12,1\%) (Tabelas 2, 3 e 4). Nota-se que existe diferença entre as frequências das espécies nas posições amostradas, onde nas guias e centros destacam-se em maior número espécies pertencentes à família Poaceae; e no beiral dos muros espécies da família Euphorbiaceae foram mais frequentes, com destaque para $P$. tenellus, que foi em número representativamente superior nesta posição de ocorrência, em relação à guia e ao centro das calçadas.

Tabela 1 - Número de plantas daninhas identificadas por família em levantamento fitossociológico realizado em calçadas públicas no município de Paraguaçu Paulista-SP

\begin{tabular}{|l|c|c|c|}
\hline \multirow{2}{*}{ Família } & \multicolumn{3}{|c|}{ Número de espécies de plantas daninhas } \\
& Guia & Calçada & Muro \\
\cline { 2 - 4 } & 5 & 5 & 5 \\
\hline 1. Poaceae & 2 & 2 & 4 \\
\hline 2. Asteraceae & 2 & 2 & 3 \\
\hline 3. Euphorbiaceae & 2 & 1 & 2 \\
\hline 4. Amaranthaceae & 1 & 1 & 1 \\
\hline 5. Malvaceae & 1 & 1 & 1 \\
\hline 6. Phyllanthaceae & 1 & 1 & 1 \\
\hline 7. Portulacaceae & 1 & 1 & 1 \\
\hline 8. Rubiaceae & 1 & - & - \\
\hline 9. Capparidaceae & 1 & - & - \\
\hline 10. Solanaceae & - & - & 1 \\
\hline 11. Cyperaceae & 17 & 14 & 19 \\
\hline Total & & & \\
\hline
\end{tabular}



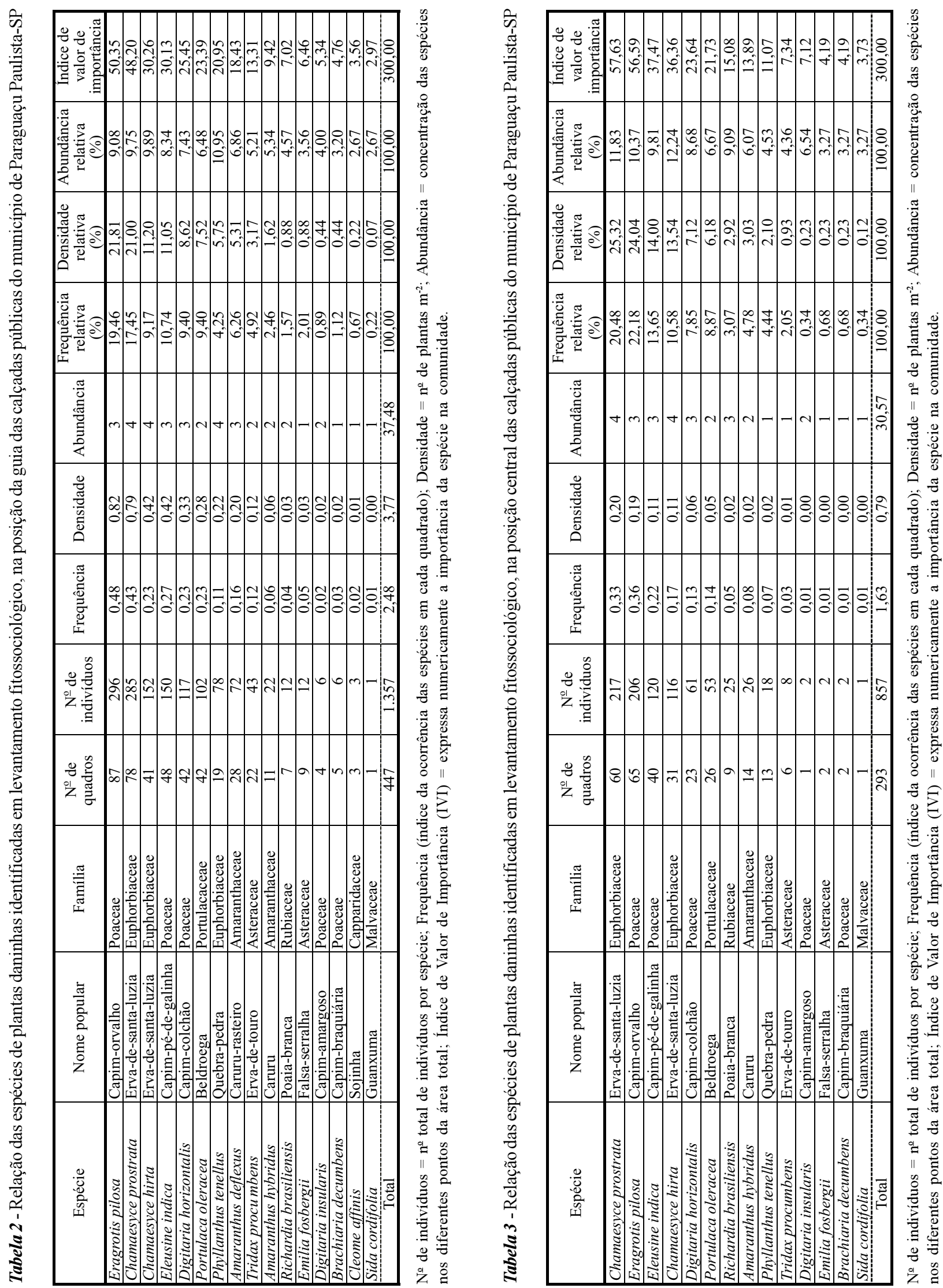

Planta Daninha, Viçosa-MG, v. 28, n. 1, p. 53-60, 2010 


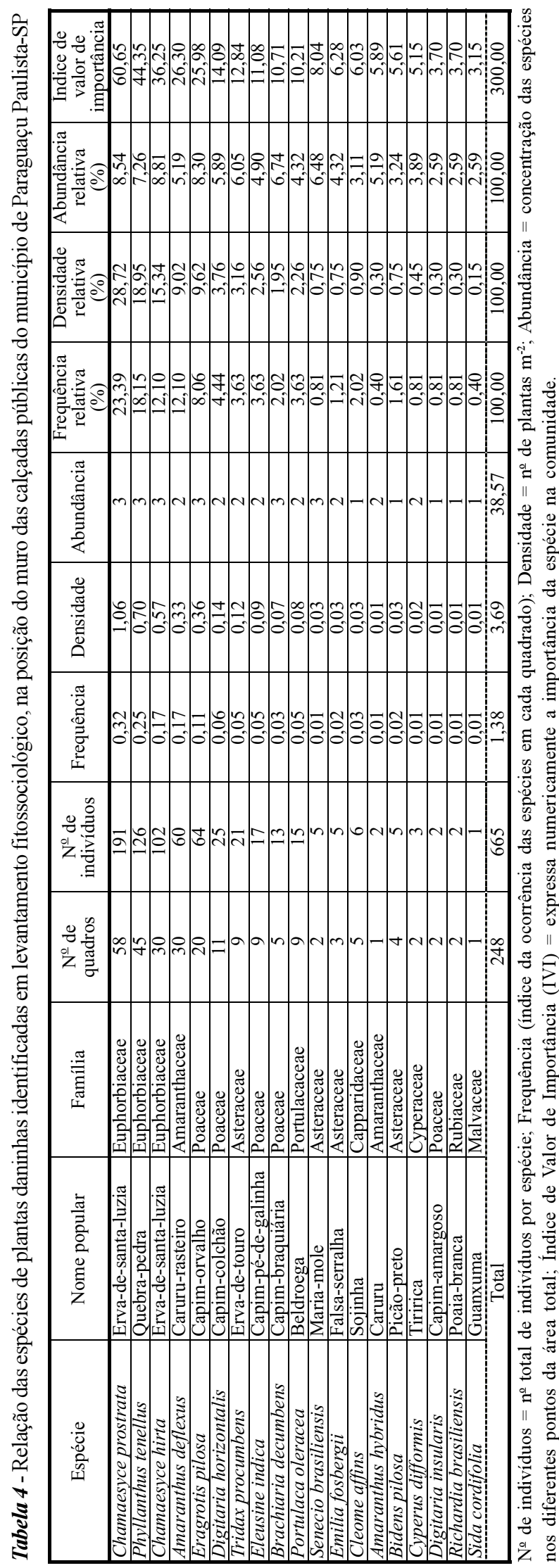

Para densidade relativa, as espécies E. pilosa, C. prostrata, C. hirta e E. indica foram as que apresentaram os maiores percentuais nas posições da guia e de centro das calçadas, com valores de 21,8 e $24,0 \%, 21,0$ e $25,3 \%, 11,2$ e $13,5 \%$ e 11,0 e $14,0 \%$, respectivamente (Tabelas 2, 3 e 4). No entanto, para a posição do beiral do muro, as espécies $C$. prostrata, $P$. tenellus e $C$. hirta, pertencentes à familia Euphorbiaceae, novamente foram as que mais se destacaram nesse parâmetro.

No que se refere à abundância relativa parâmetro importante que revela as espécies que aparecem em reboleiras, ou mesmo de forma mais concentrada nas avaliações - destacaram-se, para posição guia das calçadas, as espécies $P$. tenellus (10,9\%), C. hirta (9,9\%) e C. prostrata (9,7\%); no centro das calçadas e beiral do muro, as espécies prevalecentes foram C. hirta, C. prostrata e E. pilosa, com respectivamente 12,2 e $8,8,11,8$ e $8,5 \%, 10,3$ e 8,3\% (Tabelas 2, 3 e 4). Contudo, apesar de apenas um pequeno grupo de espécies ter se destacado em relação às frequências, densidades e abundâncias relativas nos diferentes posicionamentos das calçadas, Tivy (1993) e Schneider \& Irgang (2005) mencionam a possibilidade de ocorrerem no levantamento florístico diversos micro-habitats, diferenciados por fatores edáficos, hídricos, de luminosidade e de dimensões muito variáveis, proporcionando aumento na diversidade florística no ambiente urbano.

As espécies de plantas daninhas que apresentaram os maiores indices de valor de importância (IVI) foram: E. pilosa $(50,3)$, C. prostrata $(48,2)$, C. hirta $(30,3 \%)$ e E. indica $(30,1 \%)$, na guia das calçadas; C. prostrata $(57,6 \%)$, E. pilosa $(56,6 \%)$ e $C$. hirta $(36,4 \%)$, na região central das calçadas; e C. prostrata $(60,6 \%), P$. tenellus $(44,3 \%)$ e C. hirta $(36,2 \%)$, nos beirais dos muros nas calçadas. A família Euphorbiaceae, embora não tenha sido caracterizada como a de maior número de espécies por família (Tabela 1), apresentou as espécies de maior valor de importância do levantamento. Dessa forma, é importante ressaltar que esse resultado, para a familia Euphorbiaceae, não corrobora a maioria das informações obtidas em levantamentos 
florísticos de áreas ruderais e agrícolas, nas mais diferentes regiões brasileiras, nas quais normalmente prevalecem sobretudo as famílias Poaceae e Asteraceae.

O conhecimento prévio da composição florística das plantas daninhas em cidades, parques e jardins públicos, assim como do comportamento em diferentes condições, permite antecipar a organização de estratégias preventivas e/ou de menor impacto para adoção de medidas de controle, principalmente no caso de o manejo ser realizado com o uso de herbicidas. Nesse contexto, como foram poucas as espécies dominantes nos diferentes posicionamentos das calçadas, recomenda-se como estratégia, além da adoção de medidas de controle, a continuidade do monitoramento, a fim de evitar o aumento das principais espécies identificadas.

Embora as calçadas de vias públicas sejam consideradas um ambiente inóspito e desfavorável para o desenvolvimento vegetal, no levantamento realizado nos principais bairros do município de Paraguaçu Paulista foram identificadas 21 espécies de plantas daninhas distribuídas em 11 familias, no qual as familias Poaceae e, principalmente, Euphorbiaceae registraram os maiores índices de valor de importância (IVI), destacando-se as espécies Eragrotis pilosa, Chamaesyce prostrata, Chamaesyce hirta e Phyllanthus tenellus.

\section{LITERATURA CITADA}

ANGIOSPERM PHYLOGENY GROUP - APG II. An update of the Angiosperm Phylogeny Group classification for the orders and families of flowering plants: APG II. Bot. J. Linn. Soc., n. 141, p. 399-436, 2003.

BLANCO, H. G. Ecologia das plantas daninhas Competição de plantas daninhas em culturas brasileiras. In: BLANCO, H. G. Controle integrado de plantas daninhas. 2.ed. São Paulo: CREA, 1985. p. 42-75.

BRANDÃO, M.; BRANDÃO, H.; LACA-BUENDIA, J. P. A mata ciliar do rio Sapucaí, município de Santa Rita do Sapucaí-MG: fitossociologia. Daphne, v. 8, n. 4, p. 36-48, 1998.

CARNEIRO, A. M.; IRGANG, B. E. Origem e distribuição geográfica das espécies ruderais da Vila de Santo Amaro, General Câmara, Rio Grande do Sul. Iheringia Série Bot., v. 60, n. 2 , p. $175-188,2005$.
DEUBER, R. Manejo de plantas infestantes em área não agrícolas. In: DEUBER, R. Ciência das plantas infestantes: manejo. Campinas: Edição do autor, 1997. v. 2. p. 273-285.

ERASMO, E. A. L.; PINHEIRO, L. L. A.; COSTA, N. V. Levantamento fitossociológico das comunidades de plantas infestantes em áreas de produção de arroz irrigado cultivado sob diferentes sistemas de manejo. Planta Daninha, v. 22, n. 2, p. 195-201, 2004.

GUIMARÃES, A. J. M.; ARAÚJO, G. M., CORRÊA, G. F. Estrutura fitossociológica em área natural e antropizada de uma vereda em Uberlândia, MG. Acta Bot. Bras., v. 16, n. 3 , p. 317-329, 2002.

HOLM, L. G. et al. The world's worst weeds - distribution and biology. 2.ed. Malabar: Krieger Publishing Company, 1991. $609 \mathrm{p}$.

KISSMANN, K. G.; GROTH, D. Plantas infestantes e nocivas. 2.ed. São Paulo: BASF, 1997. Tomo I. 825 p.

KISSMANN, K. G.; GROTH, D. Plantas infestantes e nocivas. 2.ed. São Paulo: BASF, 1999. Tomo II. 978 p.

KISSMANN, K. G.; GROTH, D. Plantas infestantes e nocivas: Tomo III. 2.ed. São Paulo: BASF, 2000. Tomo III. $722 \mathrm{p}$.

LARA, J. F. R.; MACEDO, J. F.; BRANDÃO, M. Plantas daninhas em pastagens de várzeas no Estado de Minas Gerais Planta Daninha, v. 21, n. 1, p. 11-20, 2003

LORENZI, H.; SOUZA, H. M. Plantas ornamentais do Brasil: arbustivas, herbáceas e trepadeiras. 3.ed. Nova Odessa: Plantarum, 2001. 558 p.

LOREZI, H. Manual de identificação e controle de plantas daninhas: plantio direto e convencional. 6.ed. Nova Odessa: Plantarum, 2006. 339 p.

LOREZI, H. Plantas daninhas do Brasil: terrestres, aquáticas, parasitas e tóxicas. 4.ed. Nova Odessa: Plantarum, 2008. 640 p.

MACIEL, C. D. G. etal. Composição florística da comunidade infestante em gramados de Paspalum notatum no município de Assis, SP. Planta Daninha, v. 26, n. 1, p. 57-64, 2008.

MUELLER-DOMBOIS, D.; ELLENBERG, H. Aims and methods of vegetation ecology. New York: J. Wiley, 1974. $547 \mathrm{p}$.

SILVA, A. M. A.; COELHO, I. D.; MEDEIROS, P. R. Levantamento florístico das plantas daninhas em um parque público de Campina Grande, Paraíba, Brasil. Biotemas, v. 21, n. 4, p. 7-14, 2008.

Planta Daninha, Viçosa-MG, v. 28, n. 1, p. 53-60, 2010 
SOUZA, V. C.; LORENZI, H. Botânica sistemática: guia ilustrado para identificação das famílias de angiospermas da flora brasileira, baseado em APG II. Nova Odessa: Plantarum, 2005. $640 \mathrm{p}$.

SCHNEIDER, A. A.; IRGANG, B. E. Florística e fitossociologia de vegetação viária no município de Não-MeToque, Rio Grande do Sul, Brasil. Iheringia Série Bot., v. 60, n. 1, p. $49-62,2005$.

SCHNEIDER, A. A. A flora naturalizada no Estado do Rio Grande do Sul, Brasil: herbáceas subespontâneas.

Biociências, v. 15, n. 2, p. 257-268, 2007.
TIVY, J. Biogeografphy, a study of plants in the ecosphere. London: Logman, 1993. 452 p.

TUFFI SANTOS, L. D. et al. Levantamento fitossociológico em pastagens degradadas sob condições de várzeas. Planta Daninha, v. 22, n. 3, p. 343-349, 2004

YANAGIZAWA, Y. A. N. P.; MAIMONI-RODELLA, R. C. S. Composição florística e estrutura da comunidade de plantas do estrato herbáceo em áreas de cultivo de árvores frutíferas. Planta Daninha, v. 17, n. 3, p. 459-468, 1999. 